\title{
'No win, no fee', cost-shifting and the costs of civil litigation: A natural experiment*
}

\author{
Paul Fenn \\ University of Nottingham
}

\author{
Veronica Grembi \\ Copenhagen Business School \\ Baffi Center, CEIS, CIFREL
}

\author{
Neil Rickman \\ University of Surrey, \\ Erasmus School of Law
}

October 30, 2015

\begin{abstract}
Expenditure on legal services has been rising for much of the last two decades and has attracted considerable policy attention in the UK. We argue that an important reason for this increase stems from the introduction of 'no win no fee' schemes in 1995 and a subsequent amendment in 2000 which allowed claimants to shift additional costs onto losing defendants. In this paper, we describe how this may have increased expenditure on legal claims. We then test for this effect by using a dataset consisting of a large number of employers' liability claims to undertake a regression discontinuity design (RDD) in order to see whether claimants' legal costs increased following the introduction of the additional risk transfer in the year 2000. We find that costs increased by approximately $25 \%$ after the new policy was introduced, consistent with theoretical predictions. As well as providing a rare test of underlying theory (and the first with UK data), our analysis also points towards the need for more careful evaluation of policy in order to avoid unintended consequences of reform.
\end{abstract}

JEL number: K4, D04

Keywords: Litigation, Cost-shifting, Regression Discontinuity Design

${ }^{*}$ We are grateful to the editor and three anonymous referees or helpful comments, and to participants at the 2012 meeting of the European Association of Law and Economics for comments on a preliminary draft of this work. 


\section{Introduction}

Litigation is a potentially costly activity, both in the UK and elsewhere, and an important policy question in many countries involves who should be required to pay these costs. The position in English civil justice (and many other jurisdictions) for hundreds of years has been that (within reason) the loser should pay the winner's costs - typically referred to as 'costshifting'. This has long been held to have efficient case selection benefits because 'strong' cases can expect to shift their costs to the losing opponent; Posner (1973) provides an early model that demonstrates this. It has also been recognized, however, that cost-shifting can have the negative external effect of weakening cost-control incentives amongst claimants; Hause (1989) shows how this can come about in the Nash equilibrium of a game played between claimant and defendant. Evidence for both arguments can be found in Snyder and Hughes (1990) and Hughes and Snyder (1995)'s analysis of a short experiment with cost-shifting that took place in medical malpractice cases in Florida in 1985 (see Katz and Sanchirico (2010) for a survey). That experiment demonstrates the importance attached to the allocation of legal costs in many jurisdictions, but the fact that a limited experiment over thirty years ago still represents the firmest empirical evidence on the impact of cost-shifting indicates the difficulty of empirical testing when rules do not change over time. ${ }^{1}$ This paper takes advantage of a recent 'natural experiment' in the UK through the introduction of a rule change relating to the elements of costs deemed recoverable from the losing side. Given the availability of daily case-level data either side of the rule change, it offers an opportunity for the use of regression discontinuity design (RDD) techniques which have not been widely used in the economic analysis of law to date. In the process, the paper evaluates an ongoing policy debate in the UK and contributes to a significant literature on the economics of who should bear the costs of litigation.

Expenditure on civil litigation arising from personal injury (so-called 'tort' claims) has been increasing in England and Wales for the past two decades. The defendant's share of the cost of such litigation is typically borne by liability insurers. Figure 1 shows how the cost to insurers of settling claims in respect of 'Motor' and other 'Liability' claims has grown since the late 1990s, by contrast with the settlement of 'Property' claims.

\section{Figure 1 about here}

\footnotetext{
${ }^{1}$ For this reason, numerical simulation (e.g. Hylton (2002)) and experimental (e.g. see Inglis et al. (2005)) approaches have also been used to examine the effects of cost-shifting.
} 
Much of this increase has been attributed by insurers to the increases in legal costs associated with the advent of funding arrangements where the client only pays the lawyer if their case is successful - generically referred to as 'no win, no fee' schemes. In England and Wales, these are known as 'conditional fee arrangements' (CFAs), and were introduced in 1995 at a time when restrictions on public funding for legal aid were being implemented. As a result, part of the observed increase in costs could be attributable to risk premiums paid to lawyers in the form of 'success fees' (mark-ups on costs payable on successful cases) in order to secure their participation in the reallocation of risk they were thus taking on. In addition, however, much of the debate over policy in the area of legal costs since these changes has focussed on the unintended consequences of an intervention made in 2000, affecting the allocation of these success fees between claimants and defendants. In effect, this constituted an amendment to the way in which costs were shifted between winning and losing parties. The concern has been that this intervention weakened cost control incentives amongst claimants and their lawyers, and a number of policy responses have been introduced to deal with the effects of this.

Given this background, our aim is to examine the extent to which the amendment to cost-shifting in 2000, as a form of natural experiment, has had an effect on the trends we see in the latter half of Figure 1. We believe that this is important for two reasons. First, as already explained, it provides a rare opportunity to study the effects of cost-shifting rules, (and the first one in the UK). Second, it allows us to evaluate for the first time the effects of the policy as a source of increased legal costs. In addition, to the extent that subsequent policy has sought to address this in several ways, we are able to comment on these as well. ${ }^{2}$ We return to subsequent policy (including current initiatives) in the Conclusion but, first, we explain our research and how it seeks to achieve our two main objectives.

The opportunity for our research arose from a reform in 2000 that was a consequence of the need to marry the principle of cost-shifting with the advent of CFAs in 1995. Such CFAs require the claimant's lawyer to waive hourly fees if the case is lost, but allows a mark-up over these (a 'success fee') as a reward for such risk-taking if the case is won. The combination of lawyers waiving their fees if the case was lost and reductions in the availability of civil legal aid for low income clients helped CFAs to become a popular means of litigation finance towards the end of the millennium. As such, they could be argued to have widened access to

\footnotetext{
${ }^{2}$ Our focus on the reforms to CFAs in 2000 also complements existing literature which has examined the incentive effects arising from their introduction in 1995. These have been modeled by Gravelle and Waterson (1993), Emons and Garoupa (2006) and Emons (2007) and examined empirically by Fenn et al. (2002) and Fenn et al. (2006).
} 
justice, though at some cost to users because of the success fees lawyers were allowed to charge (effectively an insurance premium) in winning cases, which initially the client would pay from his/her damages. This meant that, while other costs could be shifted by a successful claimant, the same was not initially true of the success fee. Worried by this new cost to the client, in April 2000 the Government integrated the success fee into the cost-shifting rules and made the losing defendant liable for it along with the claimant's other costs. We suggest that this move to reintroduce full cost-shifting compounded the negative externality described above because it made claimants even less cost-sensitive and, as such, further weakened incentives for cost control. Because the rule change applied to cases brought relating to accidents on or after April 1st 2000, it meant that accidents prior to this date were subject to partial cost-shifting (i.e. excluding the success fee), and those on or after that date were subject to more complete cost-shifting: this is the source of the 'experiment'.

Although the arguments above are plausible, we also argue that a lack of data has typically prevented policy makers (and academics) from assessing the effects of this reform - or costshifting more generally. Snyder and Hughes (1990) and Hughes and Snyder (1995)'s work is rare because examples of shifts in cost regime are rare. Thus, for the first time, the current paper seeks to assess these arguments by analysing data on the cost and outcomes of civil legal claims in England and Wales. Our data are from a large number of individual cases which started before and after the change in recoverability in 2000 and which were collected daily, on a consistent basis, by a single, large-scale commercial insurer. The daily nature of the data allows us to use RDD techniques in order to isolate the effects of the change in policy on the costs claimed by claimants' lawyers just before or after its introduction. We find evidence consistent with the arguments above: costs rose significantly after the introduction of recoverable success fees, and the effect remains after a battery of robustness checks.

The paper is structured as follows. The next section sets out a simple model of litigation (based on Gravelle and Waterson (1993)) to explain the nature of the cost risk faced by litigants (and their lawyers) and to illustrate how this risk is exacerbated by cost-shifting. The following section then describes the key policy development upon which our empirical work focuses (the introduction of recoverable success fees) in order to illustrate the ways in which this allocation of cost risk away from the State and towards lawyers, claimants and defendants culminated in a mixture of incentives that appear to have increased costs. Section 4 presents our data and RDD methodology for examining the effects of this shift of risk on costs, as well as our results. Section 5 presents conclusions and discusses our results in the context of subsequent policy responses to the perceived effects of the April 2000 reform that we have studied. 


\section{A basic model of cost-risk in England and Wales}

Starting a legal case is somewhat akin to investing in a risky asset: there is a prospect of winning and losing the case so the ultimate return is uncertain. As a result, factors which increase the cost of the investment or the riskiness of the return may act as a disincentive to bringing (or defending) cases. In England and Wales (and many other jurisdictions), the legal rule for allocating these legal costs typically sees the loser paying the winner's costs and this increases the range of costs that a potential litigant may face. Arguably, this has both effects. In order to illustrate the effects of making the loser liable for the winner's costs ('cost-shifting') on litigation costs, consider the following stylised civil case. ${ }^{3}$

A claimant is suing a defendant for damages $x$. Her probability of winning the case is $q \in[0,1]$, which is a function of the cost (often called a 'base cost') invested by the claimant's lawyer and by the defendant. ${ }^{4}$ Using $c_{i}, i=P, D$ to represent these costs for the claimant and defendant respectively, this probability can be written as $q\left(c_{P}, c_{D}\right)$, where we assume $\partial q / \partial c_{P}>0, \partial^{2} q / \partial c_{P}^{2}<0, \partial q / \partial c_{D}<0, \partial^{2} q / \partial c_{D}{ }^{2}>0$ (i.e. investing more cost improves the claimant's chances of winning at a decreasing rate, while the defendant's expenditure lowers the claimant's chances, again at a decreasing rate). ${ }^{5}$

The claimant pays her lawyer fees: $f^{w}$ if the case is won and $f^{l}$ if it is lost. In return, the claimant can require the lawyer to invest $c_{P}$, chosen by the claimant in order to maximise her expected payoff subject to the lawyer's individual rationality constraint. Finally, to allow for the possibility of cost-shifting, we let $\tau$ be the (jurisdiction-specific) expected net transfer from defendant to claimant at the end of the case. This will affect the risks and incentives faced by the parties, in the way we describe below.

The relevant payoffs in the model can now be specified. The claimant's $(P)$ expected

\footnotetext{
${ }^{3} \mathrm{~A}$ number of authors have studied the effects of cost rules in litigation. Early analyses are due to Posner (1973) and Shavell (1982). Our presentation follows Gravelle and Waterson (1993). See Spier (2007) for a survey of how this literature links with economic models of other aspects of litigation.

${ }^{4}$ The principal-agent relationship underlying this set-up has received reasonably limited attention in papers focusing on litigation. Examples include Gravelle and Waterson (1993), who amend the current model by assuming that then lawyer's objective function is a weighted average of he and the claimant's payoffs ((1) and (2) below); Watts (1994), who looks at the benefits of attorney expertise on the outcomes of settlement bargaining; and Emons and Garoupa (2006), who consider the lawyer's choice of effort under various fee contracts. Whilst a more detailed model internalising principal-agent considerations is beyond the scope of the current paper, it would be a natural direction for future research on our question of how cost rules influence incentives for cost control in litigation.

${ }^{5}$ It is not essential to sign the cross partial $\partial^{2} q / \partial c_{P} \partial c_{D}$, though perhaps a natural suggestion would be that each party's expenditure reduces the effectiveness of the other's: $\partial^{2} q / \partial c_{P} \partial c_{D}<0$.
} 
payoff from the case is:

$$
E U_{P}=q\left(c_{P}, c_{D}\right)\left(x-f^{w}\right)-\left[1-q\left(c_{P}, c_{D}\right)\right] f^{l}+\tau
$$

while her lawyer $(L)$ expects to receive

$$
E U_{L}=q\left(c_{P}, c_{D}\right) f^{w}+\left[1-q\left(c_{P}, c_{D}\right)\right] f^{l}-c_{P}
$$

and, as already said, the claimant solves $\max _{c_{P}} E U_{P}$ given that $E U_{L} \geq 0$. The defendant's $(D)$ expected payoff assumes that he pays his lawyer the per period cost $c_{D}$ regardless of case outcome. This is a common situation since it is harder to define when the defendant has 'won' the case and, therefore, to specify an outcome-contingent fee in the way that can be done for the claimant. Thus, $D$ 's expected payoff is

$$
E U_{D}=-q\left(c_{P}, c_{D}\right) x-c_{D}-\tau
$$

Finally, we specify

$$
\tau=k\left\{q\left(c_{P}, c_{D}\right) f^{w}-\left[1-q\left(c_{P}, c_{D}\right)\right] c_{D}\right\}
$$

where $0 \leq k \leq 1$ is the degree of cost-shifting in place (e.g. $k=1$ denotes full cost-shifting). Thus, as an example, if $q=0$ and $k=1$ ), we have a claim which has no merit and which takes place under full cost-shifting. As such, we would expect the defendant to make no payments at the end of the case and the claimant to face his full legal fees and the defendant's costs. Setting $q=0$ and $k=1$ in (1) and (3) confirms this by returning $E U_{P}=-f^{l}-c_{D}$ and $E U_{D}=0$.

The model outlined above makes a number of simplifications that the literature has addressed: for example, it ignores asymmetric information between the parties, the actual duration of litigation (including the difference between filing a case, negotiating a settlement and going to trial) and the principal-agent issues that can arise in more complicated settings. These (and others) are surveyed in Spier (2007) but the model picks up the key feature of reform that we wish to highlight: the role of changes over time in who ultimately pays the costs of litigation. As such, it is a useful vehicle for examining the reforms described in Section 3 and motivating the empirical work in Section 4. The model also helps to explain the idea of a 'no win, no fee' arrangement, as is now commonly used by claimants and their lawyers for most personal injury litigation in England and Wales. One form of fee that the claimant can pay to her lawyer is an hourly fee, which compensates the lawyer for work done regardless of case outcome. In this situation, $f^{w}=f^{l}=c_{P}$. This has the possible 
disadvantage that the claimant faces her own costs when she loses. An alternative basis for legal fees that is designed to address this perceived weakness is to make payment of the fee conditional on the case outcome (and not solely the case inputs). In the US for example, the 'contingent fee' determines the fee as a percentage of damages won for the claimant: i.e. $f^{w}=\theta x, f^{l}=0$ (where $0<\theta<1$ is the contingency percentage). In England and Wales, an alternative form of output-based payment has been available since 1995: the 'conditional fee agreement' (CFA) makes payment of the fee dependent on the case outcome but the fee is calculated in relation to the lawyer's base costs, rather than damages. In particular, $f^{w}=(1+\mu) c_{P}, f^{l}=0$, where $0<\mu<1$ is a pre-specified mark-up and $\mu c_{P}$ is the 'success fee' allowable to the lawyer as a compensation for taking on the risk of losing the case. Both the contingent fee and the CFA are examples of 'no win, no fee' mechanisms where the claimant only pays a fee to her lawyer if the case is won. ${ }^{6,7}$

\subsection{Effects of cost-shifting}

We can now illustrate the effects of cost-shifting on the costs of litigation. Given our focus on the claimant's costs in our empirical analysis, we focus on her incentives when choosing costs. To the extent, as seems plausible, that claimants and defendants choose their costs in anticipation of each others' decisions, a Nash equilibrium framework would be a simple way to model such interaction. Hause (1989) recognises this and the discussion below fits readily into his Nash equilibrium analysis.

Assuming that the claimant's lawyer receives reservation utility, we can substitute from $E U_{L}=0$ in $E U_{P}$ to leave the following problem for the claimant:

$$
\max _{c_{P}} q\left(c_{P}, c_{D}\right) x-c_{P}+\tau
$$

Adopting a Cournot assumption (where the claimant expects $d c_{D} / d c_{P}=0$ ) yields the FOC

$$
\frac{\partial q}{\partial c_{P}} x-1+\frac{\partial \tau}{\partial c_{P}}=0
$$

\footnotetext{
${ }^{6}$ Several papers have specifically compared the effects of conditional and contingent fees: see Gravelle and Waterson (1993), Emons and Garoupa (2006) and Emons (2007).

${ }^{7}$ The combination of CFAs and cost-shifting still leaves the claimant exposed to the defendant's costs if the case is lost. In England and Wales it is possible to purchase an 'after-the-event' insurance policy to cover these. This does not change the nature of the arguments below so we concentrate on CFAs as set out in the current section.
} 
Notice that the absence of cost-shifting $(k=0)$ would set $\frac{\partial \tau}{\partial c_{P}}=0$ and render the choice of $c_{P}$ in (6) independent of legal fees: whatever the form they took they would simply represent a transfer between claimant and lawyer. The presence of cost-shifting $(k>0)$ changes this by making a third party (the defendant) liable for some of these fees. This is symptomatic of the externality that cost-shifting introduces into the choice of costs, as we now demonstrate.

We can examine the effects of cost-shifting on the choice of $c_{P}$ as follows. From (6) we have:

$$
\left(\frac{\partial^{2} q}{\partial c_{P}^{2}} x+\frac{\partial^{2} \tau}{\partial c_{P}^{2}}\right) d c_{P}+\frac{\partial^{2} \tau}{\partial k \partial c_{P}} d k=0
$$

Rearrangement gives

$$
\frac{d c_{P}}{d k}=-\frac{\frac{\partial^{2} \tau}{\partial k \partial c_{P}}}{\frac{\partial^{2} q}{\partial c_{P}{ }^{2}} x+\frac{\partial^{2} \tau}{\partial c_{P}{ }^{2}}}
$$

where the numerator is the second-order condition for $c_{P}$ (negative for a maximum) and $\frac{\partial^{2} \tau}{\partial k \partial c_{P}}=\frac{\partial q}{\partial c_{P}} f^{w}+q \frac{\partial f^{w}}{\partial c_{P}}+\frac{\partial q}{\partial c_{P}} c_{D}$; this will be positive provided that recovered fees rise with the costs invested by the lawyer (a reasonable assumption that is satisfied for the fees we discuss below). Thus, (8) will generally be positive, telling us that a move towards full cost-shifting raises the claimant's choice of costs monotonically, ceteris paribus, because there is a higher chance of winning (and shifting the costs - the ' $\frac{\partial q}{\partial c_{P}}$-effect' in (8)) and because, even without this, the chance to shift costs relaxes the need to keep them down (the ' $q \frac{\partial f^{w}}{\partial c_{P}}$-effect'). These constitute the negative externality created by cost-shifting, which effectively places upward pressure on litigation costs. A similar result can be demonstrated for the defendant's costs. ${ }^{8}$

In terms of Nash equilibrium analysis, we have found that a move towards cost-shifting causes the parties' reactions functions to shift out; i.e. both parties have unilateral incentives to increase costs in the face of increased cost-shifting. As is typical in Nash equilibrium, the

${ }^{8}$ The analysis mirrors that for (8). Thus, the defendant's first-order condition for choice of $c_{D}($ from $(3))$ is

$$
-\frac{\partial q}{\partial c_{D}} x-1-\frac{\partial \tau}{\partial c_{D}}=0
$$

Differentiating with respect to $c_{D}$ and $k$ then yields

$$
-\left(\frac{\partial^{2} q}{\partial c_{D}^{2}} x+\frac{\partial^{2} \tau}{\partial c_{D}^{2}}\right) d c_{D}-\frac{\partial^{2} \tau}{\partial k \partial c_{D}} d k=0
$$

which rearranges to give

$$
\frac{d c_{D}}{d k}=\frac{\frac{\partial^{2} \tau}{\partial k \partial c_{D}}}{-\frac{\partial^{2} q}{\partial c_{D}^{2}} x+\frac{\partial^{2} \tau}{\partial c_{D}^{2}}>0}
$$

The sign results form the denominator being negative by the second-order condition and the numerator being $\frac{\partial q}{\partial c_{D}}\left(f^{w}+c_{D}\right)-(1-q)<0$. 
final result will depend on how these incentives interact. Hause (1989) analyses a slightly more detailed model (with filing and settlement stages) and shows that the externality we have described causes final Nash equilibrium expenditures to increase with more cost-shifting across the majority of his simulations. Snyder and Hughes (1990) and Hughes and Snyder (1995) provide empirical evidence from Florida that cost-shifting leads to increased costs of litigation. ${ }^{9}$ Having thus illustrated the potential link between cost-shifting and litigation costs we next explain the change in cost-shifting whose effects on costs we seek to examine in Section 4.

\section{Legal fees and cost-shifting: Recoverable success fees in England and Wales}

Until 1995, the commonest means of paying for personal injury litigation in England and Wales were privately financed hourly fees, or State-sponsored legal aid. The latter was available to litigants who met criteria relating to their means and the merits of their case. By covering the expenses of such claimants, legal aid both insured their risk and protected them against the incentives for cost increases that we have described. At the same time, however, unless strong control and incentive mechanisms were in place, the State was left exposed to these same problems and while it might reasonably be regarded as an efficient risk bearer (Arrow and Lind (1970)), expenditure control actually faced several difficulties - a point made by Gray et al. (1996). Well documented expenditure increases led to numerous attempts to control legal aid expenditure during the early 1990s (Bevan et al. (1994); Gray et al. (1999)). Initially, these involved the use of fixed price contracts to force legal aid lawyers to internalise the costs of offering legally aided services. By 1999, however, the Access to Justice Act was proposing limits to the scope of legal aid, by removing personal injury cases (except medical negligence ones) from the scheme. ${ }^{10}$ In pure financial terms this

\footnotetext{
${ }^{9}$ The potential for such an externality has led to a number of proposals to amend cost-shifting rules in order to contain costs. For example, Garoupa (2009) considers whether requiring the claimant to sink upfront costs may reduce the incentive to increase expenditures at the margin as the case proceeds. He shows that the overall result depends on the interplay between incentives to start a case and whether to take it all the way to trial. Alternatively, Fenn and Rickman (2011) look at whether regulating costs may help address the problem. Of course, the extent of the need for such policies depends on the empirical size of the externality effect, to which we next turn.

${ }^{10}$ The Legal Aid Sentencing and Punishment of Offenders Act (2012) has since removed almost all civil legal aid from this remaining area of personal injury litigation on the grounds that experience with CFAs is now mature enough to allow the private sector to shoulder the cost risk that can occur in these potentially
} 
Table 1: Payoffs under two regimes

\begin{tabular}{|c|c|c|}
\hline Agent & Regime A & Regime B \\
\hline Claimant & $q^{A}\left(x-\widehat{\mu^{A} c_{P}^{A}}\right)-\left(1-q^{A}\right) c_{D}^{A}$ & $q^{B} x-\left(1-q^{B}\right) c_{D}^{B}$ \\
\hline Claimant's lawyer & $q^{A}\left(1+\mu^{A}\right) c_{P}^{A}-c_{P}^{A}$ & $q^{B}\left(1+\mu^{B}\right) c_{P}^{B}-c_{P}^{B}$ \\
\hline Defendant & $-q^{A}\left(x+c_{P}^{A}+c_{D}^{A}\right)$ & $-q^{B}\left[x+\left(1+\mu^{B}\right) c_{P}^{B}+c_{D}^{B}\right]$ \\
\hline
\end{tabular}

policy succeeded in capping (though not controlling) legal aid expenditure and, therefore, shifting responsibility for meeting legal expenditure to the private sector.

The result of this policy was a growth in the importance of CFAs, which had come into being as a result of the Access to Justice Act 1995, ending years of debate (mostly critical) about whether 'no win, no fee' arrangements should be available in England and Wales (see Rickman (1994)). Policy intervention did not end here, however, and the subsequent limiting of legal aid prompted an assessment of whether the net effect of new funding arrangements still promoted access to justice through affordable legal services. The Government concluded that this was not the case because successful claimants had to pay the success fee $\left(\mu c_{P}\right)$ from their damages, possibly deterring some from initiating legal proceedings. 'Recoverability' of the success fee was introduced to prevent this and it is this policy intervention that we seek to analyse. By making the losing defendant responsible for this additional component of cost, we suggest that recoverability effectively increased the extent of cost-shifting in England and Wales, with potential consequences for litigation costs.

We first explain the policy of 'recoverability' in more detail, with the aid of Table 1 . This presents two policy regimes (before recoverability, Regime A; and after, Regime B) and shows how risk and incentives were shifted by the movement from one to the other. The table sets $k=1$ (as we are explicitly considering policy towards litigation in England and Wales) to present the payoffs received by claimants, lawyers and defendants. Some of the variables are indexed by ' $\mathrm{A}$ ' and ' $\mathrm{B}$ ' in recognition of the fact that their values may change as we move across the two regimes.

Regime A This is the regime that was introduced in 1995. As we have seen, prior to this, personal injury litigation was largely funded by a mixture of hourly fees and legal aid so the introduction of CFAs allowed those using the former to shift some risk onto

large cases. 
their lawyer and lower the threat of a negative payoff. When legal aid was removed from most types of personal injury claim following the Access to Justice Act 1999, this further incentivised the use of CFAs (now to shift cost risk previously borne by the State). In recognition of the fact that the lawyer also bore a new risk here, the CFA allowed him to charge a pre-specified mark-up (a 'success fee', $\mu c_{P}$ ) on fees. Thus, as we have seen, $f^{w}=\left(1+\mu^{A}\right) c_{P}^{A}$ and $f^{l}=0$. Effectively, $\mu^{A} c_{P}^{A}$ was the insurance premium paid by the claimant for offloading her cost risk onto her lawyer. The entries in Regime A of Table 1 are thus (5) and (3) with $k=1$ and $\tau=q^{A} c_{P}^{A}-\left(1-q^{A}\right) c_{D}^{A}$.

Overall, Regime A distributed risk from the State to lawyers and clients in the case of claims that would previously have attracted legal aid, while redistributing it from clients to lawyers in the case of non-legal aid cases. Claimants had incentives to monitor their lawyers' base costs to the extent that they ran the risk of facing $E U_{P} \leq 0$.

Regime B In 2000, amid concerns that (some) claimants may still be deterred from litigating by the cost of the success fees in Regime A, 'recoverability' was introduced. ${ }^{11}$ This made the success fee recoverable from a losing defendant, in line with other costs under cost-shifting, and reducing her downside risk. The result is depicted in Table 1, where $\tau=q^{B}\left[\left(1+\mu^{B}\right) c_{P}^{B}\right]-\left(1-q^{B}\right) c_{D}^{B}$ in (5) and (3). As the table shows, the claimant received the intended benefit from this, while her lawyer was unaffected by the change (the term with the bracket above it in Regime $\mathrm{A}$ is transferred directly to the defendant in Regime B - see the over-bracketed term in Regime B; perhaps reflecting the continued need to encourage supply in the face of the additional risk since the removal of legal aid and introduction of CFAs). By contrast, the defendant was worse off to the tune of the success fees shifted to him if the claim was successful and because the claimant's incentives to monitor her lawyer were diluted by the reduced chance of a negative payoff, while the lawyer's incentive for cost-control were not altered.

This brief account indicates how policy towards CFAs shifted additional costs onto the defendant from 2000. When coupled with the removal of monitoring incentives on the claimant's side, the move to Regime B seems likely to have exacerbated the negative externality described in Section 2, leading to increases in the costs incurred by claimants on their cases. We now seek to test this hypothesis.

\footnotetext{
${ }^{11}$ In fact, the Access to Justice Act of 1999 formally introduced recoverability but it was not implemented until April 2000.
} 


\section{Empirical Analysis}

\subsection{Econometric strategy}

We now wish to examine the empirical effects of the changes in civil procedure we have outlined above. Specifically we aim to evaluate the impact of the shift from Regime A to Regime B on base costs, as described in Section 3. We are fortunate in having available a consistent set of claims data from an insurer with a long-standing presence in the employers' liability (EL) insurance market. ${ }^{12}$ The dataset includes all EL claims made against the insurer's policyholders and completed between January 1997 and December 2010. It includes information on the date of the accident, the date of the subsequent claim, and its closure, as well as the amount of damages agreed (if any) and a breakdown of the costs recovered on losing claims (base costs agreed, and success fees paid where relevant). This means that we are able to track the outcomes of 95,976 insurer's EL accident claims closed over a 13 year period.

Exploiting the time dimension of our dataset, which includes significant numbers of EL claims reported on a daily basis, we are able to identify the impact of the 2000 reform using a Regression Discontinuity design (RDD, see Lee and Lemieux (2010)). Using this approach we are able to compare the ultimate outcomes of claims arising from accidents occurring just before and just after April 1st 2000, the date at which success fees became recoverable from the defendant. The identification stems from the assumptions that the same types of accidents occur in a small window around the reform date and no other relevant reforms took place in the same window. If these conditions are met, it means we are comparing the same type of accidents, which are however governed by different rules of civil procedure. The difference, if any, in solicitors' base costs detected just before and just after the introduction of the reform is therefore associated with the new rules.

Considering Regime B as the treatment, the variable that assigns each accident to the treatment is the accident date, which represents our running variable. We use a parametric RDD specification with a very flexible (i.e. high order polynomial) functional form for the control function in the running variable. In particular, for each accident $a$ we regress the base costs recovered by the claimant's solicitor, and the damages paid to the claimant, on a polynomial function, $p$, of the distance between the accident date $\left(t_{a}\right)$ from the reform date

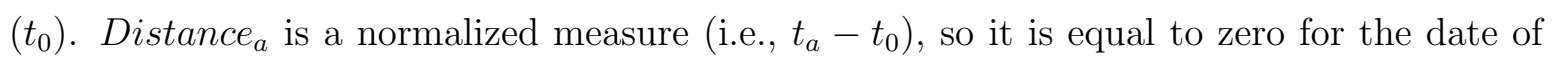

\footnotetext{
${ }^{12}$ Employers liability claims constitute an important share of the personal injury litigation market. For instance, around the time of our study (in 2000), 219,183 new EL claims were started and this constituted $29.7 \%$ of all claims, as registered with the Compensation Recovery Unit (CRU) that year.
} 
the reform and it takes positive values for each day after it and negative values for each day before it. More formally, we estimate the following model:

$$
\text { Cost }_{a}=\alpha+p\left[\text { Distance }_{a}\right]+\gamma \text { Regime } B+\varepsilon_{a}
$$

where Cost $_{a}$ is the base costs recovered in respect of accident $a, \gamma$ is the treatment coefficient, and the baseline specification of $p$ is a fifth grade polynomial, to which we add a sixth and a seventh grade specification as part of several sensitivity tests. The treatment, Regime B, is a dummy equal to one if accident $a$ occurred after the reform date (i.e., if Distance is greater than zero), and equal to zero otherwise. Even if the control function $p$ is correctly specified, in order to give a causal interpretation to the estimated coefficient, $\hat{\gamma}$, we need to make two further assumptions. First, there must be no discontinuity in the distribution of accident dates in the vicinity of the reform date, which is required to demonstrate lack of manipulation. We can easily check this assumption by running a McCrary density test (McCrary (2008)). Figure 2 shows the results of the density test around the reform date, indicating the lack of manipulation.

Figure 2, about here

Second, we need to assume that no other relevant policy was enforced on the same date as Regime B was introduced. As far as we are aware, this condition also holds. Nevertheless, to be sure that no unrelated factors caused shifts in case value or case strength at the reform date we also run similar RDD specifications for Damages (the agreed amount of damages in respect of accident $a$ ) and $\operatorname{Pr}(\text { Success })_{a}$ (a latent variable captured by a binary indicator taking the value 1 if the case is won by the claimant, and zero otherwise):

$$
\begin{gathered}
\text { Damages }_{a}=\alpha+p\left[\text { Distance }_{a}\right]+\gamma \text { Regime } B+\varepsilon_{a} \\
\operatorname{Pr}\left(\text { Success }_{a}=\alpha+p\left[\text { Distance }_{a}\right]+\gamma \text { Regime } B+\varepsilon_{a}\right.
\end{gathered}
$$

For all three outcome measures, our RDD estimations compare treated (Regime $B$ ) and control (Regime $A$ ) claims that are equal in respect of both observable and unobservable dimensions. As a further robustness check, for each outcome $\left(\right.$ Costs $_{a}$, Damages $\left._{a}, \operatorname{Pr}(\text { Success })_{a}\right)$ we estimate the impact of the reform using a local linear regression (LLR) approach. In an 
interval $\left[t_{0^{-}} h, t_{0}+h\right]$, we fit a linear function on either sides of the threshold ${ }^{13}$ :

$$
\text { Outcome }_{a}=\alpha+\gamma \text { Regime } B+\beta \text { Distance }_{a}+\delta \text { Distance }_{a} \times \text { Regime }_{B}+\varepsilon_{a}
$$

\subsection{Descriptive statistics}

In order to implement our RD design, we first restrict our analysis to a homogenous sample of observations. Out of 95,976 reported accidents, we select the 82,203 accidental injuries, dropping both illnesses and special injuries such as those associated with fires and those with unknown nature. ${ }^{14}$ Then, we check whether there is an uneven distribution of accidents across the weekdays, given the nature of EL insurance claims arising from accidents at work. ${ }^{15}$ As expected, there are significantly fewer accidents reported on Saturdays and Sundays. ${ }^{16}$ Given this systematic difference, we drop weekend accident claims from our dataset, leaving a sample of 71,201 claims. The reform date, April 1st, 2000, was a Saturday, and we therefore construct a running variable imputing the reform date to the first weekday after the reform (i.e. Monday April 3rd).

We further restrict the sample to those observations in the neighbourhood of the reform. We consider accidents which occurred in a 10-month range around the date of the reform; that is, accidents occurring in the five months before April 1st and the five months after that day (i.e. ignoring weekends, this yields a window of approximately 110 working days either side of April 1st). We then exclude claims which take longer than two years to reach an outcome. This is because our dataset consists of all claims which have reached an outcome by December 2010; if we fail to restrict the duration of claims in our analysis, it will be inevitable that those claims arising from later accident dates within our observation window will have had less time to reach an outcome than those claims arising from earlier accident dates. This would create a bias in favour of lower costs and damages in the post-reform period. ${ }^{17}$

\footnotetext{
${ }^{13}$ In the case of $\operatorname{Pr}(\text { Success })_{a}$ we estimate a probit regression using a binary indicator for a successful

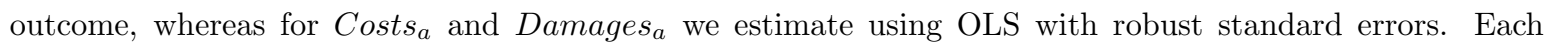
version of (12) uses the method in Imbens and Kalyanaraman (2012) to determine the optimal interval, $h$.

${ }^{14}$ Accidental injury is defined as alternative to working illness. We ran our RDD model using the nature of the accident as a dependent variable and we did not find any impact of the reform on the distribution of the types of accident before or after it.

${ }^{15}$ We also ran an equivalent check across the months of the year. The purpose was to check whether there were fewer accidents in December or over the summer. We did not detect any anomaly.

${ }^{16}$ The same is true for accidents that occurred on Fridays, compared to the other working days.

${ }^{17}$ While a restriction on the duration of claims does avoid truncation bias, we are aware that the proportion
} 
Finally, we drop the claims with damages lower than $£ 1,000$ and higher than $£ 15,000$. The rationale is related to the Civil Procedure Rules that came into force on 26th April 1999. They provided for three different 'tracks', as they were known, to which the Courts would allocate claims. Choice of track depended, in the main, on the value claimed and the length of time it might take to be heard at trial. ${ }^{18}$ By focusing on claims with damages between $£ 1,000$ and $£ 15,000$ we are using only claims which are run under the Fast Track process and we are therefore comparing like with like. This final step allows us to work on a more homogenous sample of cases.

The final sample contains 901 claims for EL covered accidents which occurred between Monday November 1st, 1999 and Friday September 1st, 2000. Table 2 reports the descriptive statistics.

Table 2, about here

Our main focus of interest is on base costs for settled claims - i.e. for those claims where a payment has been made and costs agreed in settlement of the claim within the two-year window. ${ }^{19}$ Moreover, because it seems likely that base costs will be positively correlated with case value, to check for any potential confounding effect we also explore whether any change in damages was evident for claims settling in respect of accidents occurring after the reform date. Finally, as explained above, we also focus on the probability of success to determine whether it is random across the reform date using a binary dependent variable, which takes value 1 when the claim is successful (i.e. paid) and zero otherwise. Evidence of non-randomness of the incidence of paid claims would be seen as an indication of a change in the willingness of solicitors to pursue claims further in the hope of a successful outcome rather than abandon them. This could in turn indicate a change in the selection of claims

of claims that settle within the fixed two year window can change over time. Indeed, the legal process 'stalled' during a period beyond the introduction of recoverability, for reasons discussed in Fenn and Rickman (2011). We therefore tested to confirm that the proportion of claims settling within two years was no different in our estimation windows either side of the reform date. Results are available from the authors.

${ }^{18}$ Claims are allocated to their respective track once a defendant files a defense at Court, and once the Court has asked the parties to state what directions they require the Court to make to take a case to trial. The general rule is the smaller the value of the claim the less a successful litigant can recover from her opponent in respect of his legal costs outlay. In the Fast Track the rules realistically limited recovery of the costs of a party's representative attending at trial, even if that party was entirely successful. Typically a Fast Track cost award would not cover the attendance by anybody but the barrister conducting the trial and even then the barrister's fees that were recoverable under the Fast Track regime might be much less than actually incurred.

${ }^{19}$ See Table A1 in the Appendix for the definition of the variables. 
in relation to their case strength, and would, if present, be another potentially confounding influence on base costs. Since the probability of success is assessed using a binary variable which is equal to 1 in case of positive damages and zero otherwise, when we estimate (11) we keep all the observations in the November 1st, 1999 - September 1st, 2000 interval (i.e., we do not drop observations with damages below £1,000). This means we are testing (11) on a sample of 1,319 observations.

\subsection{Results}

Results of the estimation of equations 9-11 are shown in Tables 3-5 - in particular, we present the estimated values of $\gamma$, the coefficient on the dummy for Regime B. We estimate the models using parametric RDD specifications with a flexible functional form for the control function in the running variable (the fifth, sixth, and seventh polynomial as control functions). We also add a local linear regression model with optimal bandwidth ( $h$, also reported); this allows for a spline linear control function in a smaller interval around the reform date, chosen in line with the approach in Imbens and Kalyanaraman (2012). For each specification, we test the robustness of the results shown in Panel A to the inclusion of weekdays dummies and we report the results in Panel $\mathrm{B}$. The main results on base costs indicate that these were significantly higher for accidents with dates after the reform was implemented. According to the baseline estimate, fifth order polynomial, (Panel B) the reform increases base costs by about $22 \%$ with respect to the pre-reform average value and the magnitude of the effect is similar in the other specifications (22\% in the sixth, $28 \%$ in the seventh, and $26 \%$ in the local linear specification). However, the subsidiary results on damages and the probability of success are not significant; as explained above, this seems to rule out the possibility that there was a major shift in either case value or the case selection behavior of lawyers under Regime B.

Tables 3, 4, and 5, about here

The effect on base costs reported in Table 3 is confirmed by the graphical analysis presented in Figure 3, where the impact of the reform is estimated using a spline seventh order polynomial approximation and each scatter dot represents either daily (white dots) and weekly (black dots) averages of the dependent variable. The jump around the reform date shows a higher level of base costs in the post-reform period. Figure 4 shows the same estimation for damages, confirming the results of Table 4.

Figures 3 and 4 about here 
To test the robustness of our results further, we provide an array of validity tests for the results on base costs. First, following DellaVigna and la Ferrera (2012), we run a set of regressions using fake reforms dates, namely any day between 11 and 111 days before and after the reform in order to stay sufficiently far away to the true reform date. Basically, we extend the period of interest to $-200 /+200$ working days before the real reform date, since the fake reform date could be at time -111 or at time +111 . With these fake reform dates, we do not expect to find any effect like the one detected using the true reform date. Figure 5 shows the cumulative distribution function (c.d.f.) of the results of these 200 placebo tests, normalized with respect to our baseline coefficient true specification reported in Table 3 . We expect only a few placebo estimates (i.e. not more than $5 \%$ in each tale of the c.d.f.) to be larger than the baseline results. Figure 5 shows the result of this placebo test. None of the results is larger than the baseline estimates in absolute value. This means that it is unlikely that our result is produced by random chance as opposed to a causal relationship.

Figures 5 about here

Second, we explore whether the restriction of the case values to those between $£ 1,000$ and $£ 15,000$ (i.e. "fast track" cases) affected our main result. We compare that result with two other restrictions: cases under $£ 1,000$ in value (i.e. "small claims"), and cases over $£ 1,000$ in value (i.e. "fast track" and "multitrack" combined). The results are shown in Table B1 in the Appendix. It seems that the impact of the reform had little effect on claims run through the "small claims" rules, whereas including multitrack claims along with fast track claims appears to strengthen the size of the effect somewhat. These results are supportive of our main hypothesis: the change to the recoverability rules (which did not apply to small claims) was a significant factor increasing legal costs.

Third, we also explore whether our results are sensitive to our restricting the analysis to accidents alone. A second model in which all types of injuries are included is shown alongside our core model for base costs in Table B2 in the Appendix. There is no evidence to suggest that the inclusion of all injuries weakens the results (if anything they are slightly stronger). This again is consistent with our main hypothesis as the recoverability rules applied to all personal injuries. The justification for our initial restriction to accidents only was to reduce heterogeneity, not to reflect the scope of the rules.

Finally, we seek to determine whether our findings are robust to alternative ways of dealing with the fact that the rule change occurred on a weekend, when there are relatively few accidents at work. In Table B3 in the Appendix, we compare the approach taken in our core model (i.e. to exclude weekends and to set the reform date to be on the Monday after the actual reform date - i.e. April 3rd) with two alternatives: (1) to exclude weekends 
but to keep the reform date as Saturday April 1st; (2) to include weekends, with the reform date as Saturday April 1st. We find that, providing weekends are excluded, the results are not very sensitive to whether the reform date is set at April 3rd or April 1st. The inclusion of weekends, however, weakens the results (although they remain significant for the LLR model and for the 7th polynomial). We suspect this indicates that the "thinness" of data at weekends causes estimation problems, and tends to justify our initial method of dealing with this issue.

\section{Conclusions}

The cost of litigation is important to both current and prospective claimants, defendants, lawyers and, indeed, insurers and their policy holders; as such, it can have significant implications for the performance of the legal system in delivering efficient deterrence and effective compensation. These observations make litigation cost a legitimate focus for government policy and the issue has been central to a raft of measures from both the Government and the Judiciary since the onset of recoverable success fees in 2000, up until the Legal Aid Sentencing and Punishment of Offenders Act 2012. All of these measures respond to a widespread sense that the costs (and the volume) of litigation have risen in recent years and we believe that, in order to evaluate more recent initiatives, it is important to appreciate how past ones have actually contributed to the current position.

The current paper argues that there is conceptual support for the hypothesis that the operation of 'no win, no fee' (CFA) funding in England and Wales since 2000 was at least partly responsible for the increases in the costs of civil litigation observed over that period. In particular, we show that shifting the cost of success fees to defendants under CFAs weakened monitoring incentives on the claimant's side: the resulting moral hazard exacerbated the externality implicit within the cost-shifting rule operated in England and Wales. This therefore provided a natural experiment where a change in the degree of cost shifting was observed within a single jurisdiction, and allowed the testing of one of the core hypotheses in the literature on cost allocation rules: namely, the effect on the amount of work done, and charged for, by the claimant's lawyer. Given the availability of individual claim level data with high daily volumes of recorded accidents, we were able to use a regression discontinuity design to test for the impact of the change in the rules, which took effect for accidents on or after April 1st 2000. The RDD findings are robust and consistent with the hypothesis: our estimates suggest that the introduction of recoverability may have increased base 
costs (lawyers' costs net of success fees) by about $25 \% .{ }^{20}$ This constitutes the first empirical analysis of the recoverability rules and, indeed, of cost-shifting in the UK.

Our results confirm to some extent the widespread concerns expressed by insurers, the judiciary and others about the impact of recoverable success fees. Such concerns led to a programme of policy interventions that sought to regulate the level of the costs that successful claimants could recover in high volume, low value road traffic and employers liability cases (see Fenn and Rickman (2011)). This began in 2003-05, was developed by the Ministry of Justice in 2010, and had its scope widened to include higher value claims and public liability claims in the Legal Aid Sentencing and Punishment of Offenders Act 2012, following recommendations from Lord Justice Jackson (Jackson, 2009a,b). One of Jackson's proposals, also implemented in 2012, was that the recoverability of success fees should be reversed, for reasons based on those underlying our paper. Our results lend support to this general direction of policy to the extent that they suggest that costs had been rising without commensurate changes in the nature of the cases they were funding. Our results also highlight potential dangers in the "rush" (Jackson (2009a), para 5.12, p. 30) with which recoverability was originally introduced.

Of course, while reversing the recoverability of success fees is intended to address the weak monitoring incentives that we argue have characterized much personal injury litigation since 2000, it will not solve the underlying cost concerns that arise from cost-shifting itself: we saw these in Section 2 and our results lend empirical support for their presence. Thus, in order to control the costs of litigation more generally, an issue remains about how to deal with the externality inherent in cost-shifting. Here, a role for the regulation of costs may remain, possibly along the lines of the approach that has developed since 2003 and into the 2012 legislation. Our view, however, is that such regulation needs to take place against a background of understanding about the behavioural effects it may have, and a plan for objective, empirically-based revision of the regulated costs over time (and evaluation of the policy and its effects); both of these would require suitable data collection and a mechanism for cost revision. Neither is present in the current arrangements. Whilst adopting a broader approach to cost regulation may help to reduce some of the piecemeal policy making we have studied, failure to plan for systematic revision and evaluation runs the risk of reintroducing it in years to come.

\footnotetext{
${ }^{20}$ Note that this impact on base costs relates to the experience of those claims resulting from accidents just after the change in the rules. It is likely that a learning process took place with more experience of the weaker incentives implied by the new rules, and therefore claims arising from later accidents may have had even higher costs.
} 


\section{References}

Arrow, K. J. and Lind, R. C. (1970). Uncertainty and the evaluation of public investment decisions. American Economic Review, 60, 364-378.

Bevan, G., Holland, T., and Partington, M. (1994). Organising cost-effective access to justice. Memorandum no. 9, Social Market Foundation, London.

DellaVigna, S. and la Ferrera, E. (2012). Detecting illegal arms trade. American Economic Journal: Economic Policy, 2, 26-57.

Emons, W. (2007). Conditional versus contingent fees. Oxford Economic Papers, 59(1), 89-101.

Emons, W. and Garoupa, N. (2006). US-style contingent fees and UK-style conditional fees: Agency problems and the supply of legal services. Managerial and Decision Economics, 27(5), 379-385.

Fenn, P. and Rickman, N. (2011). Fixing lawyers' fees ex ante: A case study in policy and empirical legal studies. Journal of Empirical Legal Studies. Forthcoming.

Fenn, P., Gray, A., Rickman, N., and Carrier, H. (2002). The impact of conditional fees on the selection, handling and outcomes of personal injury cases. Lord Chancellor's Department Research Report, 7/2002, London UK.

Fenn, P., Gray, A., Rickman, N., and Mansur, Y. (2006). The funding of personal injury litigation: Comparisons over time and across jurisdictions. Department of Constitutional Affairs Research Report, 2/2006, London UK.

Garoupa, N. (2009). The English rule with payments upfront. Portuguese Economic Journal, 8(3), 177-181.

Gravelle, H. S. E. and Waterson, M. (1993). No win, no fee: Some economics of contingent legal fees. Economic Journal, 103(1000), 1205-1220.

Gray, A., Fenn, P., and Rickman, N. (1996). Monitoring legal aid: Back to first principals. Hume Papers in Public Policy, 4, 24-35.

Gray, A., Fenn, P., and Rickman, N. (1999). The reform of Legal Aid in England and Wales. Fiscal Studies, 20(3), 261-286. 
Hause, J. C. (1989). Indemnity, settlement, and litigation; Or I'll be suing you. Journal of Legal Studies, 18(1), 157-179.

Hughes, J. W. and Snyder, E. A. (1995). Litigation and settlement under the English and American rules: Theory and evidence. Journal of Law and Economics, 38(1), 225-250.

Hylton, K. N. (2002). An asymmetric information model of litigation. International Review of Law and Economics, 22(2), 153-175.

Imbens, G. and Kalyanaraman, K. (2012). Optimal bandwidth choice for the regression discontinuity estimator. Review of Economic Studies, 79, 933-959.

Inglis, L., McCabe, K., Rassenti, S., Simmons, D., and Tallroth, E. (2005). Experiments on the effects of cost-shifting, court costs, and discovery on the efficient settlement of tort claims. Florida State University Law Review, 33, 89-117.

Jackson, R. (2009a). Review of civil litigation costs: (I) Interim report. The Stationery Office, London.

Jackson, R. (2009b). Review of civil litigation costs: (II) Final report. The Stationery Office, London.

Katz, A. and Sanchirico, C. (2010). Fee shifting in litigation: Survey and assessment. Research Paper 10-30, University of Pennsylvania Institute for Law and Economics.

Lee, D. and Lemieux, T. (2010). Regression discontinuities designs in economics. Journal of Economic Literature, 48, 281-355.

McCrary, J. (2008). Manipulation of the running variable in the regression discontinuity design: A density test. Journal of Econometrics, 142, 698-714.

Posner, R. S. (1973). An economic approach to legal procedure and judicial administration. Journal of Legal Studies, 2(2), 399-458.

Rickman, N. (1994). The economics of contingency fees in personal injury litigation. Oxford Review of Economic Policy, 10(1), 34-50.

Shavell, S. (1982). Suit, settlement, and trial: A theoretical analysis under alternative methods for the allocation of legal costs. Journal of Legal Studies, 11(1), 1-2.

Snyder, E. A. and Hughes, J. W. (1990). The English rule for allocating legal costs: Evidence confronts theory. Journal of Law, Economics, and Organisation, 6(2), 345-380. 
Spier, K. E. (2007). Litigation. In A. M. Polinsky and S. Shavell, editors, Handbook of Law and Economics. Elsevier North Holland.

Watts, A. (1994). Bargaining through an expert attorney. Journal of Law, Economics, and Organisation, 10(1), 168-186. 


\section{Tables and Figures}

Table 2: Outcome variables, descriptive statistics

\begin{tabular}{lcc}
\hline \hline & Regime & Regime \\
& $\mathrm{A}$ & $\mathrm{B}$ \\
\hline \hline Base Costs & $2,003.635$ & $2,159.053$ \\
& $(1,073.683)$ & $(1,120.737)$ \\
Obs. & 487 & 414 \\
& & \\
Damages & $3,563.542$ & $3,296.565$ \\
& $(2,440.781)$ & $(2,138.318)$ \\
Obs. & 487 & 414 \\
\hline \hline
\end{tabular}

Notes. The reported mean values are calculated on the sample of observation in a distance range from the reform day of 110 working days (i.e., from November 1st, 1999 to September, 1st, 2000), for claims associated to accidental injuries with damages between $£ 1,000$ and $£ 15,000$, and with a duration of 730 days. Actual values are in December 2010 Pounds, per accident. Standard deviations in parenthesis. 
Table 3: The effect of Regime B on Base Costs, RD estimates

\begin{tabular}{lcccc}
\hline \hline & $\begin{array}{c}\text { Spline } \\
\text { poly } 5^{\text {th }}\end{array}$ & $\begin{array}{c}\text { Spline } \\
\text { poly } 6^{\text {th }}\end{array}$ & $\begin{array}{c}\text { Spline } \\
\text { poly } 7^{\text {th }}\end{array}$ & $\begin{array}{c}\text { LLR } \\
h=39\end{array}$ \\
\hline \hline Panel A & & & & \\
Regime $B$ & $472.219^{* *}$ & $471.259^{* *}$ & $611.090^{* * *}$ & $513.873^{* *}$ \\
& $(207.379)$ & $(207.372)$ & $(231.316)$ & No \\
Weekday & No & No & No & \\
Dummies & & & & \\
& & & & \\
\hline
\end{tabular}

\section{Panel B}

\begin{tabular}{|c|c|c|c|c|}
\hline Regime $B$ & $\begin{array}{c}436.988^{* *} \\
(207.559)\end{array}$ & $\begin{array}{c}435.683^{* *} \\
(207.631)\end{array}$ & $\begin{array}{c}566.723^{* *} \\
(234.307)\end{array}$ & $\begin{array}{c}531.813^{* *} \\
(221.612)\end{array}$ \\
\hline
\end{tabular}

$\begin{array}{lllll}\text { Weekday } & \text { Yes } & \text { Yes } & \text { Yes } & \text { Yes }\end{array}$

Dummies

Obs.

901

901

901

319

Notes. Sample of accidents between November 1st, 1999 and September 1st, 2000 associated to damages between £1,000 and $£ 15,000$, and with a duration of 730 days. Only working days are considered (thus, $h=39$ days around the reform define the period from February 8th, 2000 to May 25th, 2000). RD estimates of the impact of the reform on Base Costs defined as costs recovered in respect of accident. Estimation methods: spline polynomial approximation with $5^{\text {th }}$-order, $6^{\text {th }}$-order or $7^{\text {th }}$-order polynomial, and Local Linear Regression (LLR). Base Cost are per claim and in December 2010 Pounds. Significance at the $10 \%$ level is represented by $*$, at the $5 \%$ level by $* *$, and at the $1 \%$ level by $* * *$. 
Table 4: The effect of Regime B on Damages, RD estimates

\begin{tabular}{lcccc}
\hline \hline & $\begin{array}{c}\text { Spline } \\
\text { poly } 5^{\text {th }}\end{array}$ & $\begin{array}{c}\text { Spline } \\
\text { poly } 6^{\text {th }}\end{array}$ & $\begin{array}{c}\text { Spline } \\
\text { poly } 7^{\text {th }}\end{array}$ & $\begin{array}{c}\text { LLR } \\
h=40\end{array}$ \\
\hline \hline & & & & \\
Regime $B$ & -7.507 & -8.294 & 638.578 & $(483.920)$ \\
& $(456.686)$ & $(457.165)$ & $(510.480)$ & No \\
Weekday & No & No & & No \\
Dummies & & & & \\
\end{tabular}

\section{Panel B}

Regime B

(442.602)

Yes

Weekday

Dummies

Obs.

$-53.150$

$(443.098)$

Yes

901

\subsection{0}

$(501.439)$

Yes

901
469.849

(493.093)

Yes

330

Notes. Sample of accidents between November 1st, 1999 and September 1st, 2000 associated to damages between £1,000 and $£ 15,000$, and with a duration of 730 days. Only working days are considered (thus, $h=40$ days around the reform define the period from February 7th, 2000 to May 26th, 2000). RD estimates of the impact of the reform on Damages defined as the agreed amount of damages in respect of accident. Estimation methods: spline polynomial approximation with $5^{\text {th }}$-order, $6^{\text {th }}$-order or $7^{\text {th }}$-order polynomial, and Local Linear Regression (LLR). Damages are per claim and in December 2010 Pounds. Significance at the $10 \%$ level is represented by *, at the $5 \%$ level by **, and at the $1 \%$ level by *** 
Table 5: The effect of Regime B on $\operatorname{Pr}($ Success), RD estimates

\begin{tabular}{lcccc}
\hline \hline & $\begin{array}{c}\text { Spline } \\
\text { poly 5 }^{\text {th }}\end{array}$ & $\begin{array}{c}\text { Spline } \\
\text { poly } 6^{\text {th }}\end{array}$ & $\begin{array}{c}\text { Spline } \\
\text { poly } 7^{\text {th }}\end{array}$ & $\begin{array}{c}\text { LLR } \\
h=40\end{array}$ \\
\hline \hline Panel A & & & & \\
Regime $B$ & & & & \\
& 0.040 & -0.004 & -0.053 & $(0.140$ \\
Weekday & $(0.262)$ & $(0.277)$ & No & No \\
Dummies & No & No & & \\
\end{tabular}

\section{Panel B}

\begin{tabular}{|c|c|c|c|c|}
\hline Regime $B$ & $\begin{array}{c}0.067 \\
(0.267)\end{array}$ & $\begin{array}{c}0.024 \\
(0.281)\end{array}$ & $\begin{array}{l}-0.024 \\
(0.321)\end{array}$ & $\begin{array}{c}0.140 \\
(0.281)\end{array}$ \\
\hline
\end{tabular}

$\begin{array}{lllll}\text { Weekday } & \text { Yes } & \text { Yes } & \text { Yes } & \text { Yes }\end{array}$

Dummies

1,319

463

$\overline{\text { Notes. Sample of accidents between November 1st, } 1999 \text { and September 1st, 2000, and with a duration of } 730 \text { days. Only }}$ working days are considered (thus, $h=40$ days around the reform define the period from February 7 th, 2000 to May 26th, 2000). RD estimates of the impact of the reform on Success a dummy equal to 1 if the case is won by the claimant, and zero otherwise. Estimation methods: spline polynomial approximation with $5^{t h}$-order, $6^{t h}$-order or $7^{t h}$-order polynomial, and Local Linear Regression (LLR). Significance at the $10 \%$ level is represented by ${ }^{*}$, at the $5 \%$ level by **, and at the $1 \%$ level by $* * *$. 
Figure 1: Trends in insurance companies' expenditure on legal claims

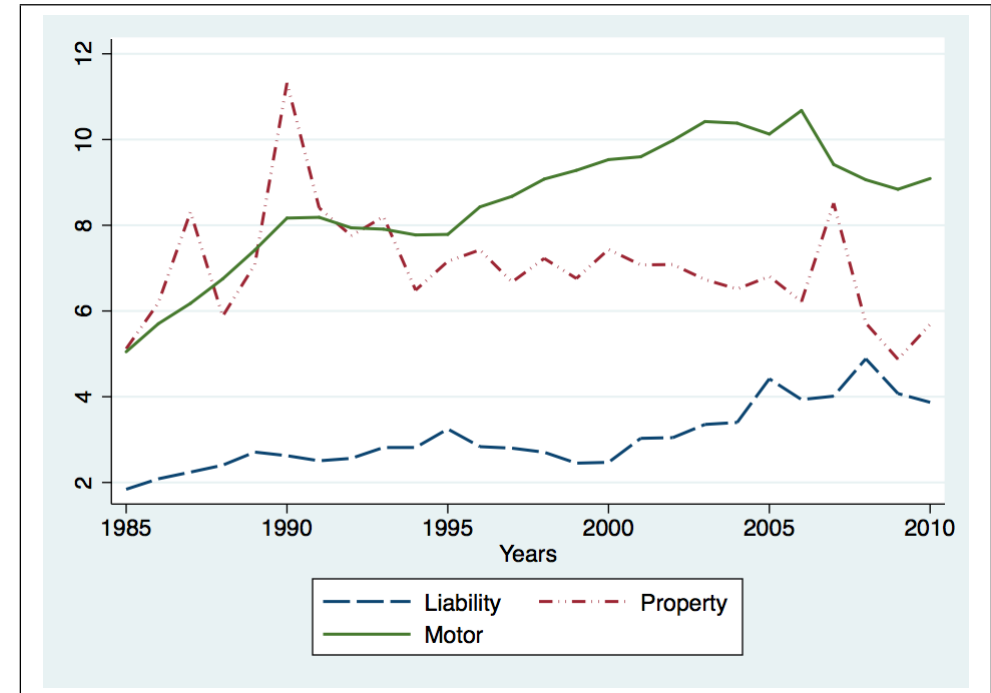

Notes: Data on the vertical axis are in million of English Pounds. Data Source: Standard and Poor's SynThesys database. 


\section{Figure 2: Density Test}

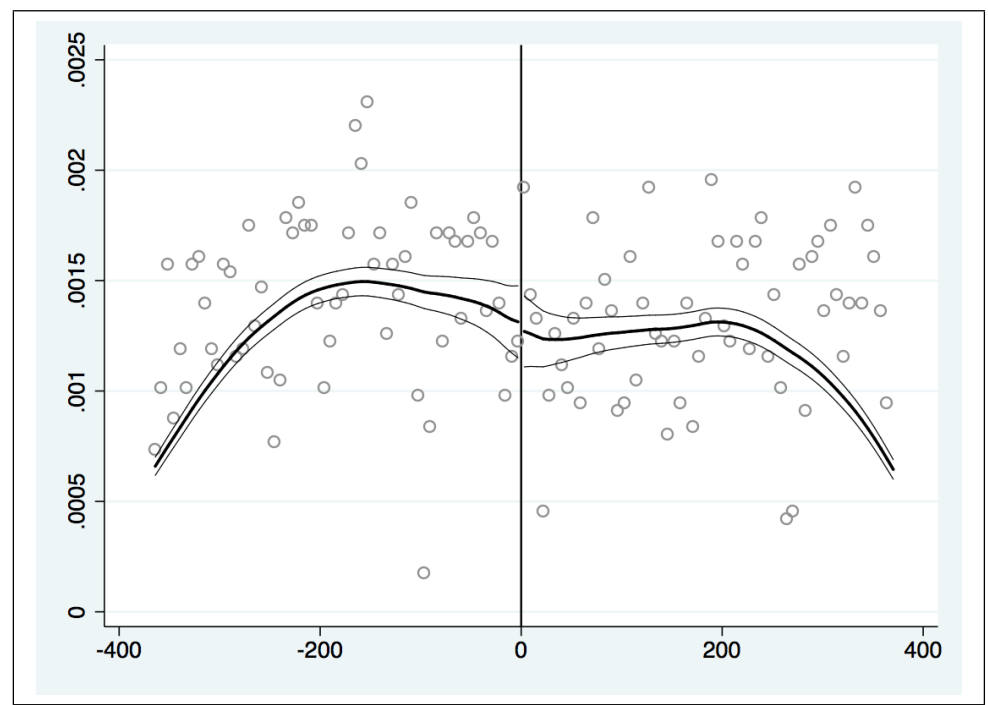

Notes: McCrary Test of the continuity at the day of the reform of the number of reported accidents per day. The central line is a spline $3^{r d}$-order polynomial fit in distance from the reform day; the lateral lines represent the $95 \%$ confidence interval. 
Figure 3: Base Costs

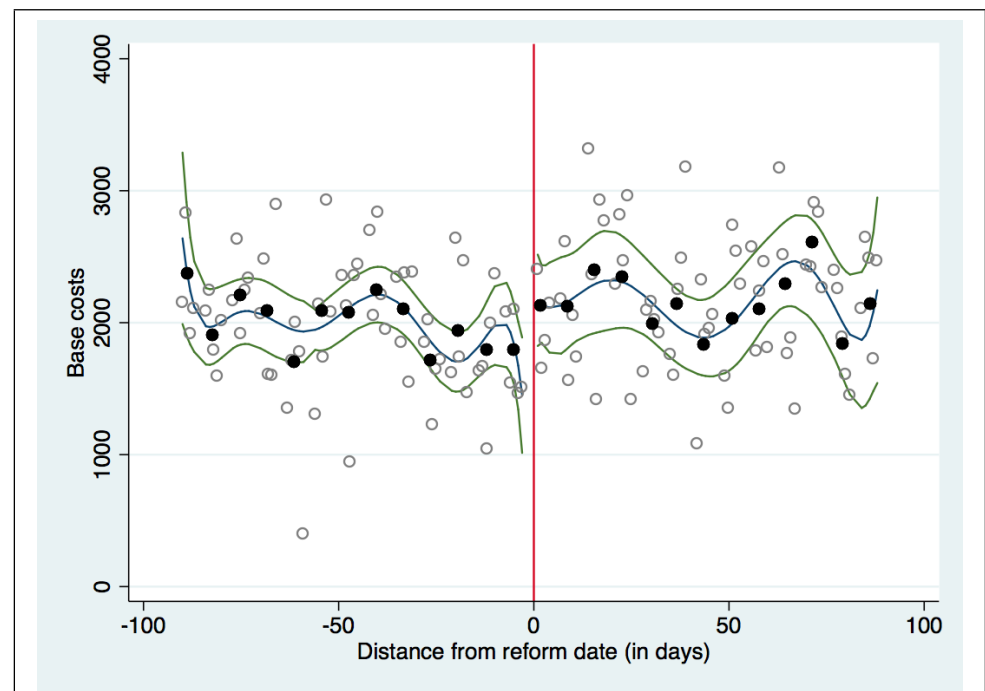

Notes: Test of the continuity at the day of the reform of Base Costs. The central line is a spline $7^{\text {rd }}$-order polynomial fit in distance from the reform day; the lateral lines represent the $95 \%$ confidence interval. Scatter points are averaged over intervals of days and weeks (black dots) 
Figure 4: Damages

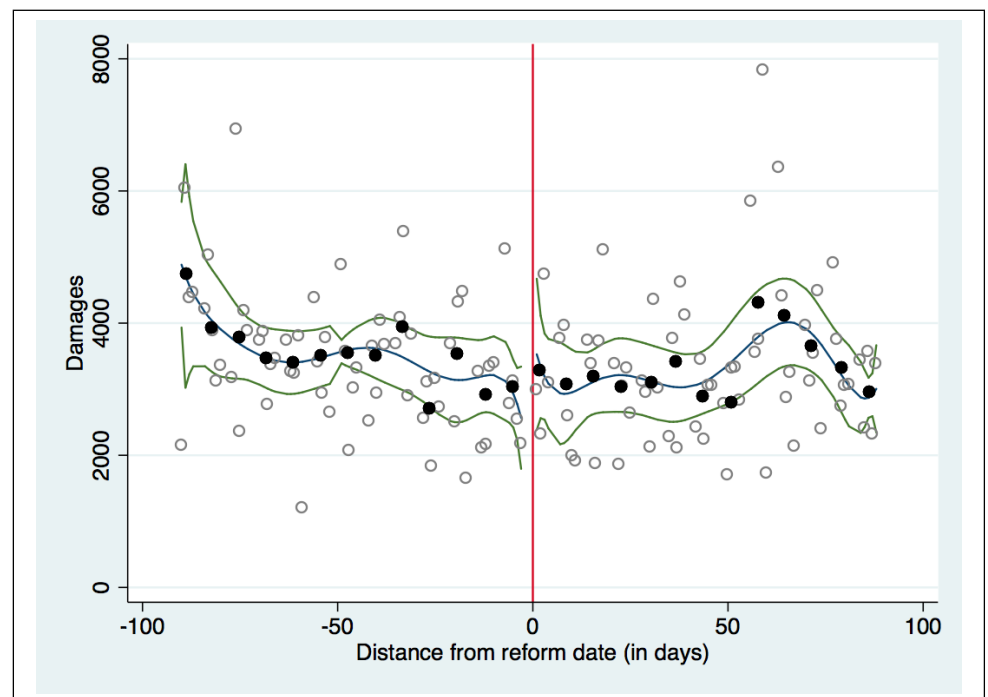

Notes: Test of the continuity at the day of the reform of Damages. The central line is a spline $7^{r d}$-order polynomial fit in distance from the reform day; the lateral lines represent the $95 \%$ confidence interval. Scatter points are averaged over intervals of days and weeks (black dots). 


\section{Figure 5: Placebo Tests for Base Costs}

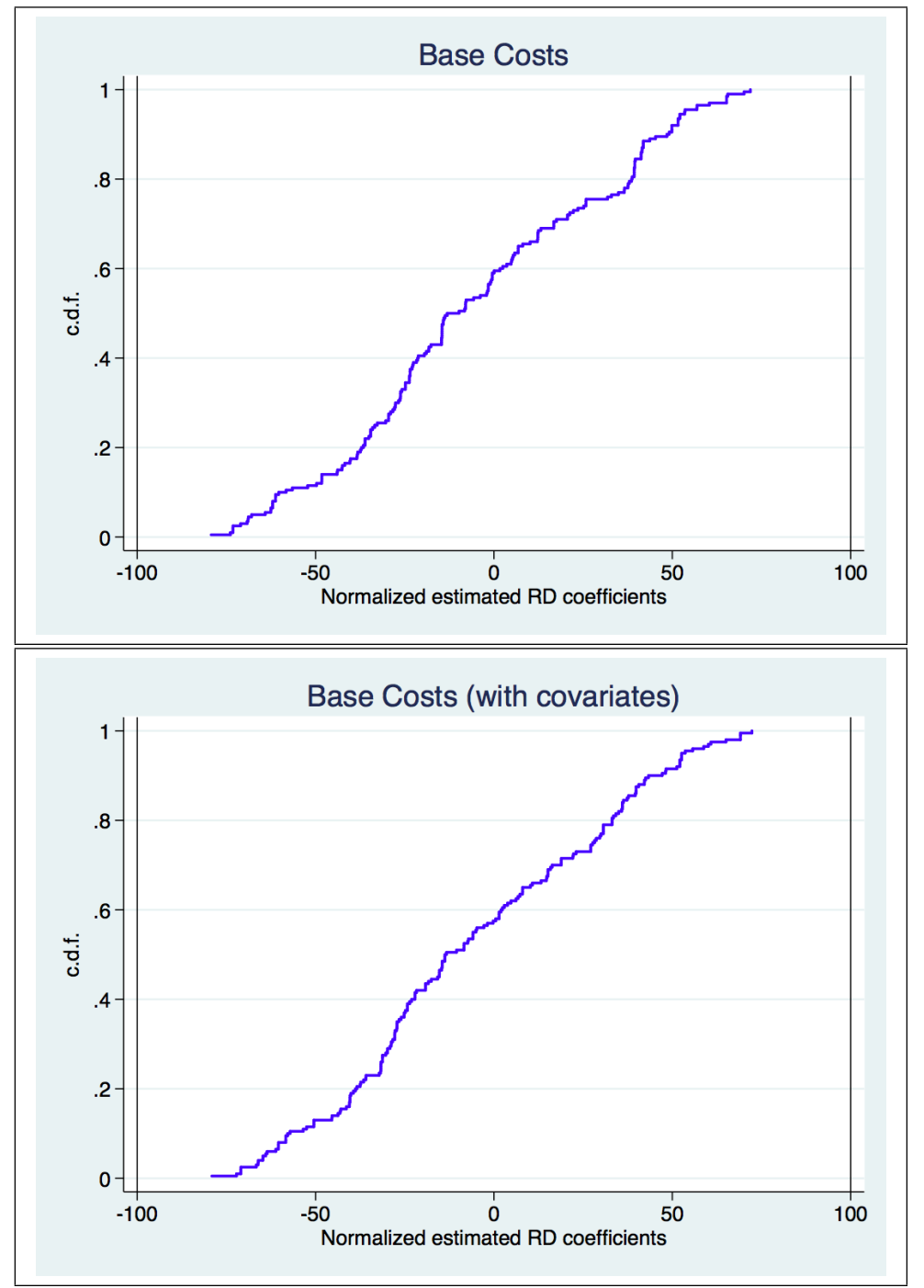

Notes. Placebo tests based on permutation methods for Base Costs. The figure reports the empirical c.d.f. of the normalized point estimates from a set of diff-in-disc estimations at 100 false thresholds below and 100 false thresholds above the true threshold at the reform date, 0 (namely, any point from day -111 and day -11 and any point from day 11 to day 111). Estimation method: spline polynomial approximation with $5^{\text {th }}$-order polynomial without covariates (upper figure) and with covariates (lower figure). Covariates include weekdays dummies. The vertical lines indicate our benchmark estimate for Base Costs from Table 3 (i.e., true coefficient normalized to 100) and its negative value. The tests are run on an interval of $+200 /-200$ working days from the true reform date, which corresponds to the period from June 28th, 1999 to January 5th, 2001. 


\section{Appendix A}

Table A1: Variables Description

\begin{tabular}{|c|c|c|}
\hline Variable & Definition & Measure \\
\hline Base Costs & $\begin{array}{l}\text { The costs (i.e. fees) incurred on the case by fee-earners, } \\
\text { including time involved in preparation, } \\
\text { attendance at and travel to court, } \\
\text { writing letters and making phone calls, } \\
\text { but not including the success fees and ATE premiums }\end{array}$ & $\begin{array}{l}\text { Continuous } \\
\text { December } 2010 \text { Pounds per claim }\end{array}$ \\
\hline Damages & The agreed amount of damages in respect of accident & $\begin{array}{l}\text { Continuous } \\
\text { December } 2010 \text { Pounds per claim }\end{array}$ \\
\hline Success & Equal to 1 if the case is won by the claimant, and 0 otherwise & Dummy \\
\hline Distance & $\begin{array}{l}\text { The distance of the date of the accident } \\
\text { from the date of the reform (April 3rd, 2000)* }\end{array}$ & Days \\
\hline
\end{tabular}

Notes: ${ }^{*}=$ Distance is calculated from the first week day after the reform, this is why rather than Saturday, April 1st, we consider Monday, April 3rd. 


\section{Appendix B}

In this appendix, we provide the results of the estimation of Equations 9 and 12 on alternative samples as defined by each table title. Results in Table B3 use the original reform date, Saturday April 1, 2000. 
Table B1: The effect of Regime B on Base Costs for different subsamples defined on the value of the claim

\begin{tabular}{|c|c|c|c|c|}
\hline & $\begin{array}{c}\text { Spline } \\
\text { poly } 5^{t h}\end{array}$ & $\begin{array}{c}\text { Spline } \\
\text { poly } 6^{t h}\end{array}$ & $\begin{array}{c}\text { Spline } \\
\text { poly } 7^{t h}\end{array}$ & $\begin{array}{c}\text { LLR } \\
h=39\end{array}$ \\
\hline \multicolumn{5}{|l|}{ Panel A } \\
\hline Claims below $£ 1,000$ & $\begin{array}{c}25.231 \\
(152.539)\end{array}$ & $\begin{array}{c}8.514 \\
(161.444)\end{array}$ & $\begin{array}{c}-36.124 \\
(192.752)\end{array}$ & $\begin{array}{l}-145.383 \\
(190.743)\end{array}$ \\
\hline Observations & 113 & 113 & 113 & 42 \\
\hline Claims between $£ 1,000$ and $£ 15,000$ & $\begin{array}{c}472.219^{* *} \\
(207.379)\end{array}$ & $\begin{array}{c}471.259^{* *} \\
(207.372)\end{array}$ & $\begin{array}{c}611.090^{* * *} \\
(231.316)\end{array}$ & $\begin{array}{c}513.873^{* *} \\
(212.705)\end{array}$ \\
\hline Obs. & 901 & 901 & 901 & 319 \\
\hline Claims equal or above $£ 1,000$ & $\begin{array}{c}602.413^{* * *} \\
(219.473)\end{array}$ & $\begin{array}{c}604.631^{* * *} \\
(219.313)\end{array}$ & $\begin{array}{c}745.722^{* * *} \\
(238.507)\end{array}$ & $\begin{array}{c}607.230^{* * * *} \\
(220.722)\end{array}$ \\
\hline Obs. & 912 & 912 & 912 & 322 \\
\hline \multicolumn{5}{|l|}{ Panel B } \\
\hline Claims below $£ 1,000$ & $\begin{array}{c}1.115 \\
(157.664)\end{array}$ & $\begin{array}{c}-22.928 \\
(162.916)\end{array}$ & $\begin{array}{c}-49.097 \\
(194.039)\end{array}$ & $\begin{array}{l}-142.144 \\
(203.712)\end{array}$ \\
\hline Observations & 113 & 113 & 113 & 42 \\
\hline Claims between $£ 1,000$ and $£ 15,000$ & $\begin{array}{c}436.988^{* *} \\
(207.559)\end{array}$ & $\begin{array}{c}435.683^{* *} \\
(207.631)\end{array}$ & $\begin{array}{c}566.723^{* *} \\
(234.307)\end{array}$ & $\begin{array}{c}531.813^{* *} \\
(221.612)\end{array}$ \\
\hline Obs. & 901 & 901 & 901 & 319 \\
\hline Claims equal or above $£ 1,000$ & $\begin{array}{c}549.651^{* *} \\
(218.078)\end{array}$ & $\begin{array}{c}551.781^{* *} \\
(217.947)\end{array}$ & $\begin{array}{c}679.324^{* * *} \\
(239.830)\end{array}$ & $\begin{array}{c}601.882^{* * * *} \\
(225.015)\end{array}$ \\
\hline Obs. & 912 & 912 & 912 & 322 \\
\hline
\end{tabular}

Notes. Sample of accidents between November 1st, 1999 and September 1st, 2000 and with a duration of 730 days. Only working days are considered (thus, $h=39$ days around the reform define the period from February 8th, 2000 to May 25th, 2000). RD estimates of the impact of the reform on Base Costs defined as costs recovered in respect of accident. In Panel $A$ we do not control for weekdays dummies, while in Panel $B$ we do control for weekdays dummies. Estimation methods: spline polynomial approximation with $5^{t h}$-order, $6^{t h}$-order or $7^{\text {th }}$-order polynomial, and Local Linear Regression (LLR). Base Cost are per claim and in December 2010 Pounds. Robust standard errors in parenthesis. Significance at the $10 \%$ level is represented by $*$, at the $5 \%$ level by $* *$, and at the $1 \%$ level by $* * *$. 
Table B2: The effect of Regime B on Base Costs on subsamples defined on the type of injuries

\begin{tabular}{cccc}
\hline \hline Spline & Spline & Spline & LLR \\
poly $5^{\text {th }}$ & poly $6^{\text {th }}$ & poly $7^{\text {th }}$ & $h=39$ \\
\hline \hline
\end{tabular}

\section{Panel A}

Only Accidents

$$
472.219^{* *}
$$

Obs.

$$
901
$$

901

901

All Type of Injuries

$$
\begin{gathered}
484.567^{* *} \\
(206.058)
\end{gathered}
$$$$
482.319^{* *}
$$

Obs. 939 939 939 330

\section{Panel B}

Only Accidents

Obs.

\section{Obs.}

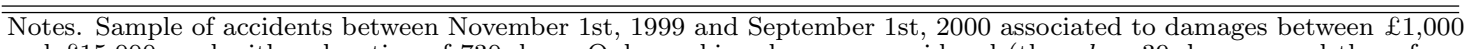
and $£ 15,000$, and with a duration of 730 days. Only working days are considered (thus, $h=39$ days around the reform define the period from February 8th, 2000 to May 25th, 2000). RD estimates of the impact of the reform on Base Costs defined as costs recovered in respect of accident. In Panel $A$ we do not control for weekdays dummies, while in Panel $B$ we do control for weekdays dummies. Estimation methods: spline polynomial approximation with $5^{\text {th }}$-order, $6^{\text {th }}$-order or $7^{\text {th }}$-order polynomial, and Local Linear Regression (LLR). Base Cost are per claim and in December 2010 Pounds. Robust standard errors in parenthesis. Significance at the $10 \%$ level is represented by *, at the $5 \%$ level by **, and at the $1 \%$ level by $* * *$. 
Table B3: The effect of Regime B on Base Costs on subsamples defined on weekends claims and with reform date April 1st

\begin{tabular}{ccccc}
\hline \hline & Spline & Spline & Spline & LLR \\
& poly $5^{\text {th }}$ & poly $6^{\text {th }}$ & poly $7^{\text {th }}$ & $h=39$ \\
\hline \hline
\end{tabular}

\section{Panel A}

Excluding Weekends and Reform date April $3 r d^{a}$

$472.219^{* *} \quad 471.259^{* *} \quad 611.090^{* * *} \quad 513.873^{* *}$

$\begin{array}{llll}(207.379) \quad(207.372) & (231.316) \quad(212.705)\end{array}$

Obs.

$$
901
$$

901

901

319

Excluding Weekends ${ }^{b}$

$466.953^{* *}$

$467.155^{* *} \quad 606.898^{* * *}$

$613.404^{* * *}$

(206.636)

$(206.805)$

(230.072)

(209.840)

Observations

912

912

912

318

Including Weekends ${ }^{c}$

$310.241 \quad 309.732 \quad 484.384^{* *} \quad 424.956^{* *}$

(196.371)

(196.444)

(220.765)

(200.982)

Obs.

1,047

1,047

1,047

371

Panel B

Excluding Weekends and Reform date April 3rd ${ }^{a}$

$436.988^{* *}$

435.683**

$566.723^{* *}$

$531.813^{* *}$

(207.559)

(207.631)

(234.307)

(221.612)

Obs.

901

901

901

319

Excluding Weekends ${ }^{b}$

$429.160 * *$

(207.153)

428.760**

$569.837^{* *}$

$624.076^{* * *}$

912

(207.286)

(232.380)

(213.738)

Observations

273.565

912

912

318

Including Weekends ${ }^{c}$

(199.186)

272.506

446.117**

395.385*

1,047

(199.248)

(224.260)

(208.417)

Obs.

1,047

1,047

371

Notes. a: Sample of accidents between November 1st, 1999 and September 1st, 2000 associated to damages between £1,000 and $£ 15,000$, and with a duration of 730 days. $b$ Sample of accidents between October 28th, 1999 and August 30 th, 2000 associated to damages between $£ 1,000$ and $£ 15,000$, and with a duration of 730 days. $c$ : Sample of accidents between December 13th, 1999 and July 19th, 2000 associated to damages between $£ 1,000$ and $£ 15,000$, and with a duration of 730 days $(h=39$ days around the reform define the period from February 22 nd, 2000 to May 9 th, 2000). RD estimates of the impact of the reform on Base Costs defined as costs recovered in respect of accident. In Panel $A$ we do not control for weekdays dummies, while in Panel $B$ we do control for weekdays dummies. Estimation methods: spline polynomial approximation with $5^{\text {th }}$-order, $6^{\text {th }}$-order or $7^{\text {th }}$-order polynomial, and Local Linear Regression (LLR). Base Cost are per claim and in December 2010 Pounds. Robust standard errors in parenthesis. Significance at the $10 \%$ level is represented by $*$, at the $5 \%$ level by **, and at the $1 \%$ level by ***. 